\title{
EL MUSEO UNIVERSAL PINTADO POR SÍ MISMO: TRAYECTORIA DE UN PROYECTO EDITORIAL (1857-1869)
}

\author{
Diego CHOZAS RuIZ-BELloso \\ pedagogico@casadeespanha.com.br \\ Casa de España de Río de Janeiro / Universidad de Zaragoza
}

\section{Resumen}

Tras algunos titubeos iniciales, en 1860 El Museo Universal consolida su estructura y su línea editorial de la mano del director literario Nemesio Fernández Cuesta, quien equilibra los contenidos literarios y los artísticos, si bien abre un frente de batalla por la libertad de expresión que cuestiona permanentemente la identidad de la revista, lo que a Fernández Cuesta terminará costándole el puesto. Estas vacilaciones acerca del papel de los contenidos políticos en la publicación las heredarán los sucesivos directores de esta revista en principio «no política» (aunque nacionalista en su ideología) que se singularizó sobre todo en su época por la calidad de sus ilustraciones.

Palabras clave: El Museo Universal, revista ilustrada, Nemesio Fernández Cuesta, censura.

\begin{abstract}
After some initial hesitancies, Nemesio Fernández Cuesta will fix the structure and the editorial project of El Museo Universal in 1860. However, this editor, responsible for the literary contents achieve the same quality and relevance of the artistic part, often will ask about the publication's nature, defying the limits imposed by censors and forcing finally his dismissal. Essentially, El Museo Universal was mainly an illustrated review, but the problem about what to do with the political information would continue until the end, affecting all the successive editors of this remarkable publication.
\end{abstract}

Keywords: El Museo Universal, illustrated review, Nemesio Fernández Cuesta, censors.

Anales, 26, 2014, pp. 127-145

DOI: 10.14198/ALEUA.2014.26.05 
El 15 de enero de 1857 salía a la venta en Madrid el primer número de El Museo Universal, publicación de los editores José Gaspar Maristany y José Roig Oliveras $^{1}$ que se proponía llegar a la altura de las mejores revistas ilustradas europeas.

Un año más tarde, concretamente en el primer artículo publicado en 1858, titulado «Introducción», el historiador José Puiggarí, figura de gran peso durante los primeros años de la publicación, se enorgullecía de que este objetivo hubiera sido alcanzado con medios exclusivamente españoles:

Dejando aparte la opinión de los extraños, no siempre desfavorable, los propios fueron los primeros en sonreír con incredulidad, cuando a vista de nuestro prospecto, parecieron dudar de que en la corte de España, por los años de gracia de 1857, hubiese dibujantes, grabadores, impresores y hasta literatos, capaces de seguir de cerca a las Ilustrated London News, al Bristish Museum, Illustriche Zeitung, Magasin Pittoresque y otros periódicos que suelen pasar por oráculos en el género $\left(1858, \mathrm{n} .^{\circ} 1\right)$.

La elevada calidad material de la publicación, nunca vista hasta entonces en España $^{2}$, se apoyaba por una parte en la moderna máquina de imprimir de la fundición alemana Koenig et Bauer (casa que ganaría una medalla de primera clase en la Exposición Universal de París de 1867)³ ${ }^{3}$ cuyos tipos se estrenaban además cada año ${ }^{4}$, por otra, en lo más granado de la segunda generación de grabadores españoles, salidos del taller de Vicente Castelló, y encabezados por Bernardo Rico y Carlos Capuz (Riego, 2001, p. 132), que ya habían asimilado perfectamente las más recientes técnicas europeas del grabado en madera y que supieron aportar a El Museo Universal notables y visibles mejorías frente a publicaciones ilustradas anteriores como el Semanario Pintoresco Español, La Ilustración, o El Artista.

En las propias páginas de El Museo Universal podemos encontrar pruebas del reconocimiento que los grabados de esta publicación recibieron ya

1. La empresa Gaspar y Roig conformó «una de las iniciativas editoriales más activas del siglo» a decir de Jesús A. Martínez Martín (2001, p. 50).

2. «Era imposible ofrecer al lector español cualquier tipo de representación después de haber conocido el alto nivel al que llegó la revista de Gaspar y Roig», dice Bernardo Riego (2001, p. 215) al respecto de la exigencia a la que iba a ser sometida La Ilustración Española y Americana, sucesora de El Museo Universal.

3. «Establecimiento tipográfico de Gaspar y Roig - Salón de máquinas», El Museo Universal, n. ${ }^{\circ} 4$ de 1868.

4. «Así Semanario Popular se refunde con El Museo Universal, primer periódico ilustrado original en España, donde la mayor nitidez del papel, los tipos estrenados cada año, los excelentes grabados y los artículos de eminentes literatos harán olvidar al público su mayor precio» (Semanario Popular, 23 de febrero de 1865, apud Gómez Aparicio, 1967, p. 481). 
en su época, como premios ${ }^{5}$ o menciones elogiosas en la prensa extranjera ${ }^{6}$, pero incluso mucho después de la extinción de la revista (que tuvo lugar en 1869), y con la debida perspectiva que da el tiempo, siguió hablándose de los excelentes grabados de El Museo como su marca más característica: Pedro de Madrazo, con motivo del veinticinco aniversario de La Ilustración Española y Americana, publicó en enero de 1882 el artículo «Los periódicos ilustrados de Madrid», en el que El Museo Universal adquiría voz propia y decía: «yo levanté de repente el arte del grabado en madera, de la vergonzosa postración en que yacía, a la altura y dignidad que goza en los países más adelantados» (Riego, 2001, p. 112). Doce años más tarde, en sus Apuntes para un catálogo de periódicos madrileños desde el año 1661 al 1870, Eugenio de Hartzenbusch describía El Museo Universal como una «importante publicación, que recuerda el Semanario pintoresco español, pero muy mejorado en la parte artística» (Englekirk, 1955). Pero distanciándonos aún más en el tiempo, y ya bien adentrados en el siglo Xx, nos encontramos con la acreditada opinión de la especialista en iconografía y grabados Elena Páez Ríos, quien, en la breve introducción al catálogo de contenidos de El Museo Universal, que ella misma elaboró y publicó en 1952 dentro de la colección de índices de publicaciones periódicas del C.S.I.C., escribe: «Consta cada número de la revista -quincenal en sus tres primeros años- de ocho páginas, de 304 por $214 \mathrm{~mm}$, magnífica de presentación en cuanto a papel e impresión, y, sobre todo, se da en ella una importancia tal a la parte ilustrativa, que en sus trece años de existencia recogió casi íntegramente el último esplendor del grabado en madera» (p. IX). $\mathrm{Y}$ apenas tres años después, en el único artículo que se ha escrito hasta hoy con una visión global sobre El Museo Universal, John Englekirk insistía en la aventajada calidad gráfica de esta revista afirmando que era «superior in physicall make-up to all earlier and contemporary Spanish illustrated reviews» (1955, pp. 366-367).

En efecto, a pesar del indudable interés de los textos de El Museo Universal, de los que pasaremos a hablar enseguida, debemos insistir en su naturaleza de revista ilustrada, pues será esta característica, esta especialidad, lo que le permita destacar entre la maraña de los ciento cincuenta periódicos (la mitad madrileños) que se publicaban en España hacia 1857 (Seoane, 1968, pp. 244-245).

5. En la «Revista de la semana» del n 5 de 1865, León Galindo y de Vera anuncia que Bernardo Rico ha ganado un premio por los grabados publicados en El Museo.

6. La publicación extranjera que menciona Ruiz Aguilera en su «Revista de la semana» del n. ${ }^{\circ} 44$ de 1867 es la Ilustración Americana de Frank Leslie, de Nueva York. 
No olvidemos que el propio título de la publicación, El Museo Universal, quiere destacar el carácter ilustrado de la revista, siguiendo el ejemplo del Semanario Pintoresco Español ${ }^{7}$, La Ilustración o el Museo de las Familias, de manera que el nombre de nuestro periódico daría a entender la pretensión de registrar en imágenes todos los lugares y todos los asuntos.

Antes de cerrar el asunto de las ilustraciones, debemos detenernos brevemente en el grabado que apareció en la cabecera de El Museo Universal desde su primer número hasta el último, pues se trata de una evidente alegoría de lo que esta publicación pretende ser; una manera de presentarse visualmente a los lectores que se adoptó como una de las señas de identidad más características y permanentes de la revista ${ }^{8}$ :

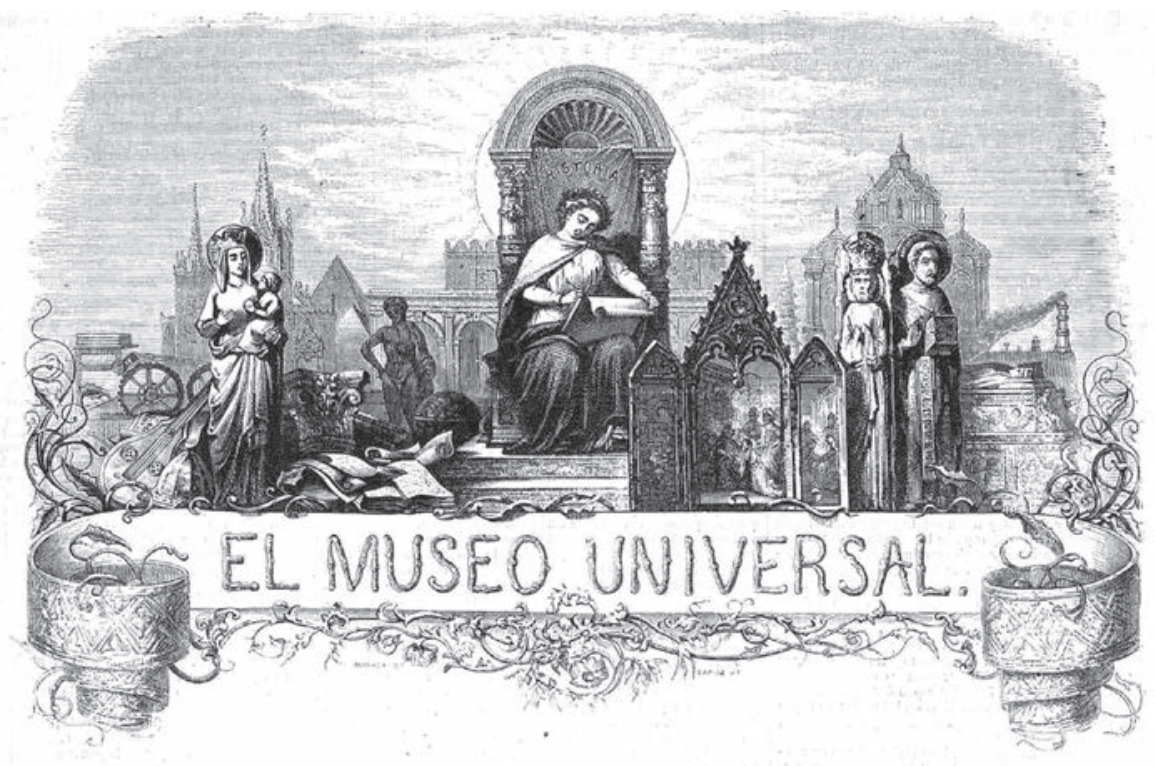

Firmado por Múgica y Capuz, el grabado está presidido por una figura femenina en un trono que representa a la Historia y que toma nota de lo que ve a su alrededor. Esta figura se encuentra rodeada de un buen número de productos

7. Recordemos que una de las primeras acepciones de «pintoresco» fue «lo digno de ser pintado».

8. El grabado ha sido extraído de uno de los ejemplares digitalizados para la Biblioteca Virtual de Prensa Histórica, cuya colección de El Museo Universal ha sido la fuente primaria fundamental para este trabajo, complementada cuando ha sido necesario por las colecciones de la Hemeroteca Digital de la Biblioteca Nacional y de la Biblioteca Virtual Miguel de Cervantes. 
culturales, en su mayoría obras de arte, en una disposición un tanto caótica, como son: un tríptico que parece contener pinturas religiosas, edificaciones de diferentes estilos arquitectónicos, (incluyéndose al fondo las pirámides de Egipto y una torre oriental), y esculturas de diversas épocas. Pero también se muestran en el grabado un globo terráqueo, unos legajos antiguos, un instrumento musical (un laúd árabe, en apariencia) o, detrás de este, una máquina con ruedas dentadas, que guarda relación de simetría con otro elemento moderno que encontramos a la misma altura, pero en el extremo derecho de la imagen: lo que parece la alta chimenea humeante de una fábrica.

¿Corresponde este grabado con lo que vamos a encontrar en El Museo Universal a lo largo de su historia? Ciertamente, el protagonismo de la arquitectura, frente al resto de las bellas artes, aparece bien reflejado en esta ilustración. Además, la presencia de los adelantos científicos e industriales es también una constante de la revista, así como los artículos de «Geografía y viajes» representados por el globo terráqueo. Por lo demás, se diría por la imagen que pintura, escultura, música y literatura van a tener un tratamiento equilibrado en las páginas de El Museo, cuando no va a ser así: la pintura, la escultura y la música van a recibir escasa atención, y raramente serán abordadas como asunto, mientras que la literatura (posiblemente simbolizada por los legajos que quedan a los pies de la figura central) va a tener una importancia crucial en la revista, no menor que la de los artículos histórico-descriptivos que hacen referencia a edificios monumentales.

La literatura se despliega en cada número de El Museo en forma de textos de creación (relatos y novelas, poemas, artículos de costumbres) pero también como objeto de análisis, con frecuentes reseñas de novedades, esporádicos artículos eruditos dedicados a clásicos como El Quijote, y constantes críticas de las representaciones teatrales madrileñas, comentadas en la «Revista de la semana» o en una específica «Revista de teatros».

El caso es que El Museo Universal, que por su calidad material y por la pericia de sus grabadores no podía dejar de destacar en su faceta gráfica, tampoco descuidó sus contenidos puramente literarios, adquiriendo un rápido prestigio que lo hizo muy atractivo para jóvenes y prometedores escritores como Ricardo Puente y Brañas, quien, en su brillante presentación como colaborador durante el tercer año de andadura de El Museo Universal, escribía: «Venimos de otras publicaciones literarias también, siquiera no hayan brillado tanto como El Museo en el cielo de nuestra literatura» $\left(1859, \mathrm{n}^{\circ}{ }^{\circ} 18\right)$.

En efecto, hasta ese momento El Museo Universal había contado con un equipo de colaboradores asiduos de gran altura, como Manuel Murguía, Ventura Ruiz Aguilera, Antonio Ribot y Fontseré, Juan de Dios de la Rada o un 
descollante Pedro Antonio de Alarcón ${ }^{9}$, y también se habían podido ver en esos tres primeros años las firmas de Mesonero Romanos, Pi y Margall, Emilio Castelar, Gaspar Nuñez de Arce, Carlos Rubio, Manuel Fernández y González o Eulogio Florentino Sanz, quien en el número 9 de 1857 publicó su histórica traducción de algunos poemas de Heine. Y en los años siguientes irían sumándose otros nombres que han pasado a la historia de la literatura española, como Antonio de Trueba, Rosalía de Castro ${ }^{10}$, Juan Eugenio Hartzenbusch, Ramón de Campoamor, Gustavo Adolfo Bécquer, José Zorrilla o Juan Valera ${ }^{11}$.

Esta calidad en los contenidos literarios puede atribuirse a la iniciativa y al buen tino inicial de Nemesio Fernández $\mathrm{Cuesta}^{12}$, director de la revista desde 1857 hasta el final de 1864, esto es, durante los ocho primeros años de vida de El Museo Universal. En los primeros años, a decir verdad, llega a intuirse una sorda pugna entre los contenidos históricos y los literarios o, en todo caso, una vacilación en la línea editorial que acabará en un equilibrio de fuerzas, en la atribución de una importancia similar a los textos históricoartísticos y a los textos de creación literaria, cuando a estos últimos no se les había reservado un papel tan esencial en la primera concepción de la revista.

Mientras que a lo largo de la historia de nuestra publicación encontramos innumerables ejemplos de colaboradores que definen El Museo Universal

9. En las «Revistas de la quincena» de los números 10 y 12 de 1858, Nemesio Fernández Cuesta anuncia que ha encargado determinado artículo (sobre el viaje de la corte a Toledo) a un «entendido escritor» y a un "concienzudo escritor», respectivamente, comedido elogio a un colaborador de El Museo que no podía ser en la época un autor muy destacado, pues su nombre era una información prescindible.

10. Firmando como Rosalía Castro de Murguía, publica por primera vez, y en gallego, en el $n^{\circ} 47$ de 1861. Se trata del poema «iAdeus qu' eu voume!», texto fundamental del rexurdimento gallego.

11. Cualquier panorámica general de El Museo Universal resultaría injusta y deficiente si no mencionase al periodista «A.» como uno de los grandes proveedores de contenidos de la revista durante toda la época de Fernández Cuesta e incluso durante algunos años posteriores. Sus artículos, sobre los asuntos más dispares, están presentes en prácticamente todos los números de la primera época, de manera que este discreto e infaltable escritor puede considerarse parte esencial del sostén estructural de El Museo y representa como nadie la naturaleza heterogénea de la publicación. Sabemos que el «A» que firmó las «Traducciones e imitaciones del poeta alemán Heine» en el n. ${ }^{\circ} 46$ de 1861 fue el amigo de Bécquer Augusto Ferrán porque luego estos poemas fueron incluidos en las obras completas de este (Cubría, 1999, p. 108) pero eso no garantiza que los numerosísimos y muy variados artículos escritos por «A» sean todos de Ferrán. Tampoco debemos olvidar a José Pastor de la Roca, que en el tramo final de la historia de El Museo tuvo una participación muy importante, con abundantes colaboraciones.

12. La Enciclopedia Espasa incluye completas biografías para la mayoría de los directores literarios de El Museo Universal, a las que remitimos al curioso lector. No son tan accesibles las informaciones sobre Nicolás Díaz Benjumea, así que resumiremos en su momento (nota 29) su bio-bibliografía. 
como periódico literario, llamativamente, el mismísimo editor y director José Gaspar, en una de sus raras apariciones, diría en la temprana fecha del 30 de agosto de 1857 que el «especial carácter» de El Museo es su «calidad de periódico científico y artístico $»^{13}$. Si esto aparecía en el n ${ }^{\circ} 16$, ya en el número siguiente leemos una nota sin firma que, con el título de "Jarrón árabe», comienza con las palabras: «Siendo las bellas artes para nuestra publicación si no el único y principal objeto, el de mayor estima e importancia», etc. ${ }^{14}$ Asimismo, es significativo que, tanto en 1857 como en 1858, los primeros textos del año fueran encargados al historiador del arte José Puiggarí, que hablaba en nombre del conjunto de la revista, dejando sentir claramente el peso de su ascendiente. Parece ser que, tal y como evidencia la figura central del grabado de la cabecera, en un primer momento se quiso que la Historia tuviese un papel crucial en el seno de El Museo, y el encargado de aportar esta orientación a la revista sería inicialmente el historiador catalán, que en el $n^{\circ}$ 1 de 1857 escribía:

[...] solo los españoles podemos apreciar y hacer apreciar lo que España fue, y lo que será algún día, porque nadie cuenta para este objeto con mayores elementos y recursos.

Una publicación consagrada a esta tarea, bien que sin desprenderse de un cierto carácter general, como se quiere en nuestra época de universal propaganda, tiene trazado un noble, anchuroso y curiosísimo camino.

Esta es pues la gran línea maestra trazada originalmente para El Museo Universal: un intento de reconstruir la imagen y el prestigio de España desde España, frente a la visión deformada e incompleta extendida en el extranjero, revisando sus episodios históricos gloriosos y destacando todo el patrimonio artístico legado por ese pasado de grandeza; una reacción de orgullo ante la baja autoestima nacional que, ante la imposibilidad de equipararse a los países más industrializados del momento, acude a otro terreno de batalla en el que España pueda batirse en condiciones de igualdad: el terreno del arte y de la historia.

13. Se trata de una materia de mediana extensión titulada «Esposición de Agricultura» (1857, n. ${ }^{\circ}$ 16) en la que José Gaspar plasma otros comentarios interesantes, incidiendo en la prioridad de los grabados al afirmar que «por medio de artículos descriptivos y razonados, ofreceremos al lector lo que el dibujo y el grabado no pueden ofrecer, la parte, digámoslo así, económica y moral de la solemnidad y de sus resultados».

14. Estas palabras del primer año de El Museo contrastan curiosamente con otras que encontramos en el penúltimo: «[...] pero en atención a que este periódico se ocupa con preferencia de literatura [...]», dirá Salvador Costanzo en los «Caprichos literarios pueriles e insustanciales» que publicó en el n 27 de 1868. 
Solo que la influencia de Nemesio Fernández Cuesta iría creciendo paulatinamente, y con ella la importancia de los contenidos literarios: hasta el número 13 de 1857, la «Revista de la quincena» que cerraba cada entrega de El Museo era apenas firmada con las siglas «N. F. C.», y como director de la publicación figuraba, al final del número, don José Gaspar. A partir del número 14, no obstante, aparece por primera vez el nombre completo de Nemesio Fernández Cuesta, y lo hace precedido de una pequeña nota que dice: «Por esta revista, y por todos los demás artículos no firmados en este número», lo que da a entender que al periodista se le ha atribuido una mayor responsabilidad. Finalmente, el primer artículo de 1859, en lugar de venir firmado por Puiggarí, aparece sin firma, de manera que deducimos que este relevante artículo ha sido escrito por Fernández Cuesta. Lo mismo ocurrirá en 1860, cuando, además, la publicación empieza a ser semanal y la revista de la quincena que cerraba todos los números se traslada a la portada en forma de «revista de la semana», pasando a dar máxima relevancia a los últimos acontecimientos, narrados por el director literario, frente a los artículos variados, casi siempre histórico-artísticos, que se habían venido destacando en la portada durante los años precedentes. De esta manera, Fernández Cuesta no realizaba apenas un cambio en la estructura de la publicación, sino que daba un paso importante para alterar su naturaleza, aproximándola a los periódicos políticos, empeño que acabará siendo incompatible con el cargo de director de una revista literaria y que precipitará la salida de Nemesio Fernández Cuesta de El Museo Universal tras graves enfrentamientos con los censores.

En efecto, no bastaba con declararse «Periódico de ciencias, literatura, artes, industria y conocimientos útiles» en la portadilla de cada tomo anual, sino que el hecho de sacar a la luz pública una revista «no política» tenía importantes implicaciones legales que suponían la limitación de los contenidos y la aplicación de medidas coercitivas en caso de desvíos.

En el propio Museo vamos a encontrar muy pronto indicios de los asuntos que a un periódico literario no le está permitido publicar: ya en el $n^{\circ} 1$ de 1858, Pedro Antonio de Alarcón se preguntaba en el artículo «El año nuevo» si en los próximos doce meses se daría alguna novedad de calado, como que la prensa pasase a ser libre, y será el propio Alarcón quien, en el $n^{\circ} 11$ de ese mismo año, a propósito del viaje de la corte a Alicante y Valencia, se justifique por extenso ante los lectores por centrarse en asuntos literarios y no tocar los políticos, materia vedada para El Museo Universal. Siguiendo con Alarcón, en el artículo «España y los franceses», publicado en el $n^{\circ} 11$ de 1859, escribe estas esclarecedoras líneas: 
Pero hemos llegado a los tiempos presentes. Seguir hablando de historia equivaldría a hablar de política, y nosotros escribimos en un periódico literario: veamos, pues, de encaminar nuestra cuestión al terreno de las costumbres, abandonando la esfera de los gobiernos.

También Nemesio Fernández Cuesta aludió varias veces en sus revistas a la naturaleza «no política» de El Museo (1858, n. ${ }^{\circ} 7 ; 1859$, n. $^{\circ} 22,1860$, n. $^{\circ} 22$ ) pero, no conformado con la menguada libertad de información, empezó a tensar la cuerda de la censura, opinando sobre la polémica del sufragio universal al hilo de los acontecimientos italianos (1860, n. $\left.{ }^{\circ} 16\right)$, afirmando que, como periódico histórico, podía limitarse a consignar hechos de la actualidad política mientras no los comentase ${ }^{15}$, hablando abiertamente sobre política exterior española ${ }^{16}$, incluyendo citas literales de periódicos políticos «autorizados» ${ }^{17}$, o recurriendo a la risa amarga, como cuando en la revista del n $n^{\circ}$ de 1860 escribe: «También el gobierno español ha presentado a las Cortes varios proyectos de reformas que... ¡Pero, guarda Pablo! Ya íbamos a penetrar en terreno vedado. Hablemos de teatro».

La crítica de Fernández Cuesta a la censura es cada vez más abierta y ácida, como demuestra el transparente fragmento que sigue, extraído de la revista del $n^{\circ} 24$ de 1862:

Sobre la cuestión mejicana se han presentado al Congreso y al Senado los documentos diplomáticos; y la semana última se empleó en la discusión relativa a este punto en el primero de los cuerpos mencionados. Nada diremos

15. Dice Fernández Cuesta en la revista del n 26 de 1860 a propósito del último manifiesto de don Juan de Borbón: «Veremos el efecto que estos hechos que hemos narrado pura y simplemente y sobre los cuales no podemos ni debemos hacer comentarios porque lo prohíbe la índole del periódico, causan en la actitud de los que hasta aquí conocimos con el nombre de carlistas». Asimismo, en la revista del n ${ }^{\circ} 2$ de 1862, refiriéndose a la invasión de México por tropas europeas, escribe: «Limitado El Museo a dar cuenta de los sucesos, en cuanto tienen de tales sin entrar a considerarles bajo un aspecto político determinado, no puede imitar a sus colegas nacionales y extranjeros y por tanto espondrá sumariamente, según su costumbre, las noticias recibidas desde que apareció su último número». Y en la revista del n. ${ }^{\circ} 20$ de 1864 ocurre algo análogo, reproduciendo Fernández Cuesta una polémica entre políticos españoles considerándola un hecho histórico contemporáneo.

16. En el $n^{\circ} 1$ de 1860 justifica la atención va a prestarse a la Guerra de África diciendo que los progresos militares arrastran el progreso de las artes, y en el no 39 de 1861 se detiene bastante en la insumisión del rector del Real Colegio de España en Bolonia pero, evidentemente, es consciente de estar tocando el límite de lo permitido, pues escribe: «No profundizamos esta cuestión limitándonos a los hechos, porque necesitaríamos salirnos del terreno de los periódicos no políticos».

17. En la revista del n. ${ }^{\circ} 43$ de 1860, Fernández Cuesta narra el atentado a la reina en la Puerta del Sol apoyándose en fragmentos de El Diario Español, Correspondencia y Época.

Anales, 26, 2014, pp. 127-145 
acerca de ella ni de sus resultados por ser asunto prohibido para periódicos que como El Museo no tienen carácter político. Nosotros somos un periódico sin carácter de ese género y eso es lo que nos caracteriza. Por lo demás, lo que pudiéramos decir no vale ciertamente los 15.000 duros que costaría el derecho de decirlo.

Nemesio Fernández Cuesta estaba haciendo referencia a la extraordinariamente restrictiva Ley Nocedal, que estuvo en vigor del 13 de julio de 1857 al 22 de junio de 1863, y que exigía una fianza previa de 300.000 reales ( 15.000 pesos duros, por tanto) para quien quisiera editar un periódico de naturaleza política, además de aumentar drásticamente las penas, y dar amplios poderes a los gobernadores y a jueces de primera instancia para resolver cuestiones de prensa, sin recurso posible para las multas impuestas (Valls, 1988, p. 129). $\mathrm{Al}$ año siguiente, Fernández Cuesta volvería a quejarse con amargura de esta normativa, lamentando no poder comentar el discurso de la reina como las publicaciones políticas «en atención a que no habiendo depositado los 15.000 duros en el Banco, no ofrecemos la garantía suficiente ni somos de bastante peso para emitir una opinión» $\left(1863, n^{\circ}{ }^{\circ} 45\right)$.

Finalmente, en una revista de la semana que terminaría siendo decisiva (la del n 51 de 1863) Fernández Cuesta saluda insólitamente al nuevo «fiscal de imprenta» en una suerte de carta abierta, y reconoce que al saber que el anterior, el Sr. Chacón, que solía mutilarle las revistas, «había pasado a otro destino, bailamos la chacona». La osadía del director literario de El Museo Universal no se vio cohibida cuando Ricardo Chacón recuperó más adelante el puesto de censor, atreviéndose Fernández Cuesta a dirigirse abiertamente a él en el $\mathrm{n}^{\circ} 11$ de 1864 empleando una vez más un tono burlón totalmente contrario al decoro. En la revista anterior, la del n. ${ }^{\circ} 10$ de 1864, Fernández Cuesta había pisado en terreno incuestionablemente político al emitir su opinión sobre una crisis ministerial, y a lo largo del resto del año seguirá desafiando a la censura y defendiendo la libertad de expresión, como cuando en el n. ${ }^{\circ} 20$ «apunta» el hecho de que se hayan prohibido las reuniones y manifestaciones públicas sin autorización, o como cuando en el n. ${ }^{\circ} 45$ critica, esta vez diáfanamente, una disposición gubernamental que supone de hecho el fin de la libertad de cátedra. En la última revista del año 1864, la del n. ${ }^{\circ}$ 52, volverá a cargar directamente contra la censura, denunciando que la que se aplicó a una obra de Picón no respondía a motivos morales, sino políticos.

En el primer número de 1865, no obstante, encontramos a otra persona, León Galindo y de Vera, firmando la primera revista de la semana del año, en la que ni siquiera se menciona a su antecesor, que durante tantos años había estado al frente de El Museo Universal. Como única pista del posible motivo 
para la destitución de Fernández Cuesta se anuncia la intención de que la revista sea inocente hasta el punto de que cualquier dama o niño puedan hojearla sin cuidado, lo que podría entenderse como un propósito de enmienda frente a la carga ideológica que el anterior director le estaba imprimiendo a la publicación.

Unas semanas más tarde, concretamente en el número 4 de ese año, aparece una peculiar explicación -cifrada- del editor José Gaspar, que llevaba muchos años sin firmar un texto de El Museo. Se trata de la respuesta pública a una carta de Nemesio Fernández Cuesta que, sin embargo, no se incluye en este número. Tampoco se mencionan aquí directamente los motivos del cese, pero se deja entender que este no fue en absoluto voluntario ni pactado, y que fue comunicado por escrito. En su cuidadoso texto, José Gaspar se centra apenas en la protesta de Nemesio Fernández Cuesta, quien habría querido ver en el breve texto de presentación de la nueva «Revista de teatros» un ataque (inexistente, según el editor) a su anterior trabajo como crítico teatral.

En todo caso, hay dos párrafos en el mensaje de José Gaspar que sí parecen apuntar a la cuestión de fondo, y que extracto a continuación:

[...] La rectitud y la imparcialidad, ni pueden ser novedades en los artículos escritos por el señor Cuesta, ni en periódicos de los que nos envanecemos de ser directores.

[...] Lo que le escribimos al privarnos de sus Revistas se lo repetimos ahora: las páginas de El Museo siguen siempre abiertas para que las honre con sus artículos; y las páginas del El Museo no las hubiera ofrecido, no las ofrecería a persona que se conceptuase parcial y de juicios torcidos el director de $E l$ Museo.

¿A qué insistir en la necesidad de imparcialidad si se estaba hablando de críticas teatrales? En realidad, esta nota de José Gaspar parece una velada explicación dirigida a todos los suscriptores que, sin duda, debieron echar en falta las bien condimentadas Revistas de Fernández Cuesta: sin poder reconocer abierta y públicamente que El Museo había estado albergando a un articulista políticamente «parcial», algo prohibido para un periódico literario, lo deja entender como si estuviese refiriéndose a un asunto más liviano, si bien el rarísimo acontecimiento de que José Gaspar tomase la palabra en su publicación daba una noción mucho más exacta de la gravedad del momento.

Sin duda Gaspar sentía una gran simpatía hacia Fernández Cuesta, e incluso hacia su postura ideológica, pues en caso contrario este habría sido destituido mucho antes (llevaba cinco años desafiando a la censura) ${ }^{18}$, pero

18. También apoya esta tesis el hecho de que a partir del nº 40 de 1868 (del 4 de octubre), Ventura Ruiz Aguilera, entonces director literario, en nombre de El Museo Universal, 
hay que tener en cuenta que el 12 de abril de 1863 había fallecido José Roig ${ }^{19}$, quien figuraba hasta entonces en todos los números como «Editor responsable», con lo que los cargos de Director y Editor recayeron a partir de entonces en José Gaspar, concentrándose también sobre él la responsabilidad penal ante todo lo vertido en El Museo. Por lo tanto, las declaraciones cada vez más extremadas de Fernández Cuesta, que culminaron en la repetida ridiculización del «fiscal de prensa», no solo ponían en peligro la continuidad de El Museo, sino que podían implicar también graves consecuencias para el editor que las respaldaba.

La salida de Fernández Cuesta de El Museo Universal coincidió, según varios estudiosos, con el inicio de la decadencia de este periódico: Elena Páez (1952, pp. IX-XII) se fijó en el declive de su calidad material y en la disminución del número de grabados originales, especialmente acentuada en $1869^{20}$; mucho más evidente resulta la inestabilidad en el cargo de los directores literarios (seis entre 1865 y 1869), y en los últimos años llega a comentarse en varias ocasiones las dificultades que atraviesa la revista, debido sobre todo a la escasez de suscriptores, como se deja entender en la «Revista de la semana» del n 46 de 1867, firmada por Ventura Ruiz Aguilera, en la que se habla de la extrema dificultad que encuentra un periódico literario en España para alcanzar los 1.500 suscriptores $^{21}$. Encontramos en la propia publicación algunos indicios más sutiles de estos problemas, como los textos y grabados de autopromoción que menudean en los últimos tiempos ${ }^{22}$, pero la confirmación más transparente de la crisis del periódico la veremos solamente en la nota de despedida del último número de El Museo Universal, donde Abelardo de Campos, que había adquirido el periódico al comenzar 1869, no se refería apenas a las difíciles circunstancias políticas de los últimos meses cuando se excusaba de esta manera por la situación crítica que venía arrastrando el periódico:

La empresa, que desde principios de este año adquirió de sus fundadores este periódico, se propuso avanzar en la senda que aquellos ya tenían trazada, y

apoye sin ambages la reciente revolución y critique duramente el régimen anterior. En ese número, José Gaspar aparecía aún al final del número como «Director y Editor responsable», pero a partir del número siguiente, sin duda por la indefinición legal que trajo la revolución, esta información es suprimida.

19. Ver la nota necrológica que abre el $\mathrm{n}^{\circ} 16$ de 1863.

20. Esta investigadora notó que la calidad del papel empeoró justamente a partir de 1865

21. «En general, el periódico político que aquí logra reunir 3.000 suscriptores ha puesto una pica en Flandes; el periódico literario que reúne la mitad, la ha puesto en Pekín».

22. «Librería de los editores (calle del Príncipe) cuando se expone El Museo Universal», grabado del n. ${ }^{\circ} 1$ de 1867; «El Museo Universal -Año duodécimo- 1868», n 50 de 1867; «Establecimiento tipográfico de Gaspar y Roig - Sala de máquinas», en el n 4 de 1868 . 
desde luego habría realizado su propósito, si las circunstancias críticas porque [sic] atravesamos se lo hubieran permitido.

Ha hecho no obstante, cuanto le ha sido posible para cubrir el compromiso que contrajo, y si del todo no pudo lograrlo hasta ahora, no ha sido por falta de voluntad ni por restricción en los medios; sin embargo, cree haber aprendido lo bastante en este año de costosísima prueba para poder ofrecer, como hoy lo hace, una publicación que supere en mucho a la que hasta aquí ha dado a luz $[\ldots]\left(1869\right.$, n. $\left.^{\circ} 48\right)$

Abelardo de Campos se estaba refiriendo a la Ilustración Española y America$n a^{23}$, que ya se venía anunciando en números anteriores $\left(1869\right.$, n. $^{\circ} 31$ y n. $\left.{ }^{\circ} 45\right)$ como resultado de una profunda modificación y modernización de El Museo Universal. Hasta tal punto la Ilustración Española y Americana se presentó ante los lectores como continuación de nuestro periódico, que se publicaba con el subtítulo de «Museo Universal - Periódico de Ciencias, Artes, Literatura, Industria y Conocimientos útiles», y en la portada del primer número se indicaba que el año de publicación era el XIV, incluyendo, por lo tanto, los trece años previos de El Museo (B. Márquez, 2005, pp. 192-193)24. Además, el grabado de cabecera de la nueva revista no parece más que una modernización del que se mostraba en la portada de El Museo Universal25.

A pesar de la situación crítica de los últimos tiempos de El Museo Universal a la que venimos aludiendo, este periódico nunca dejó de tener prestigio y, a decir de Gómez Aparicio (1967, p. 482), «lo que se proponía don Abelardo de Campos con esa adquisición era privar de cualquier competencia a esta nueva revista» ilustrada que él estaba fundando.

Por esta razón, si bien el último director literario de El Museo Universal escondió su nombre tras las iniciales «N.C.» al firmar las Revistas de los catorce últimos números de la publicación, ya abocada al cierre, los anteriores

23. Miguel B. Márquez habla del paso de una publicación a otra en «D. Aberlardo de Campos y la Ilustración Española y Americana» (revista Ámbitos, n 13-14, 2005, pp. 185209), que incluye una interesante declaración de Julio Nombela, a quien se le encargó negociar la compra de El Museo Universal, y que explica que Abelardo de Campos se había hecho millonario gracias a su revista La Moda Elegante Ilustrada.

24. Sin embargo, el grupo de grabadores que lideraba Bernardo Rico pasó en bloque a $\mathrm{La}$ Ilustración de Madrid, según apunta Bernardo Riego (2001, p. 227).

25. Debo esta observación a Leonardo Romero. En efecto, el grabado de cabecera de $\mathrm{La}$ Ilustración Española y Americana representa igualmente toda una serie de edificios monumentales de diversos estilos y rescata algunos elementos como el globo terráqueo o los símbolos de las artes (una paleta de pintor, un busto o una lira) que pasan a un primerísimo plano, dejando en los extremos derecho e izquierdo de la imagen las dos únicas verdaderas novedades conceptuales del grabado: dos escenas americanas que parecen mostrar, entre la vegetación tropical, los orígenes indígenas y la posterior explotación económica del continente con mano de obra esclava. 
directores de contenidos desempeñaron su cargo con conciencia de estar ocupando un lugar de relevancia en las letras españolas; un hueco, a decir verdad, que había dejado Nemesio Fernández Cuesta tras ocho años en un puesto y una función que él mismo había ido levantando poco a poco a su medida, y en el que, por consiguiente, no terminaría de encajar a la perfección ninguno de sus sucesores.

En 1865, con Galindo y de Vera en la dirección literaria, las novedades en los contenidos de El Museo fueron mínimas (la Revista de teatros de la que ya hemos hablado, algunos grabados novedosos con figurines de moda, o los problemas de ajedrez de la última página) manteniendo por lo demás la misma estructura que había fijado Fernández Cuesta, con la «Revista de la semana» abriendo cada número, si bien al nuevo director literario le tocó la imposible tarea de mantener el atractivo de esta sección noticiera estándole totalmente vedado hacer la más mínima referencia a la actualidad política. Lo intentó durante veintiséis números, pero al número siguiente incluyó la más dura insinuación contra la reina de toda la historia de El Museo quejándose del lujo y el despilfarro en tiempos de crisis, y diciendo que eso ocurre cuando gobierna una casa una mujer de moda. Y ya en el n. ${ }^{\circ} 28$ se permitiría ironizar sobre el bozal de la censura al escribir en la revista: «Y en España no ocurre más por ahora que digno de contar sea... ¿Sonríen mis lectores? Pues rectificaré. No ocurre nada más que a mí me sea lícito referirles». En esta misma línea, tras hablar en el n. ${ }^{\circ} 40$ de un caso de censura en Francia en que se condenó al infractor al destierro, Galindo de Vera comenta: «Nos parece bien: a nosotros todo nos parece bien».

Tal vez fue precisamente la alargada sombra de Fernández Cuesta (junto a la censura) la principal responsable de que León Galindo de Vera, intentando cumplir con las expectativas, no encontrase sin embargo el tono adecuado y acabase naufragando en su labor de revistero, dando paso a Gustavo Adolfo Bécquer en enero de 1866. Este realizó un trabajo sobrio, puramente periodístico, sin pretender competir con la chispa del primer director de El Museo Universal, pero confeccionando por eso mismo una sección deslucida que no terminaba de encontrar su sentido: lograr, en efecto, un resumen «no político» de las noticias de la semana era pretender la cuadratura del círculo ${ }^{26}$.

26. Entendemos así que las escasas referencias a la actualidad nacional no se deben a la postura conservadora de Bécquer, como sostiene Seoane (1968, p. 260), sino a la propia naturaleza «no política» del periódico. El propio Bécquer explica esta circunstancia en la revista del $n^{\circ} 10$ de 1866: «Respecto a política interior continuaremos siendo tan parcos como la índole de nuestro periódico exige». Y en la Revista del $n^{\circ} 11$, tal vez aludiendo a los problemas con la censura de Fernández Cuesta, sigue explicándose: 
Meses después, al recuperar Bécquer su puesto de censor de novelas, la dirección literaria de El Museo Universal recayó en el poeta Ventura Ruiz Aguilera, veterano colaborador del periódico, que se mantendría en el puesto desde el no 33 de 1866 hasta el no 41 de 1868, dejando en ese momento la dirección «de la parte literaria» de El Museo para incorporarse a un alto cargo del gobierno revolucionario, según se nos explica en una nota del n ${ }^{\circ} 42$.

Ruiz Aguilera, por lo tanto, estaría al frente de El Museo algo más de dos años, durante los cuales tampoco se aprecia ninguna novedad importante ni en los contenidos ni en la estructura de la publicación. En todo caso, parece iniciativa de Ruiz Aguilera la voluntad de destacar con epígrafes, a partir de 1868, las secciones fijas (y también las más variables) que componen $E l$ Museo: «Monumentos artísticos», «Costumbres populares», «Geografía y viajes», «Inventos», «Historia», «Literatura», «Álbum poético», «Novelas y cuadros de costumbres», «Tipos», «Estudios morales», «Ceremonias religiosas», «Estudios arqueológicos», «Apuntes biográficos», «Bibliografía», etc., etc. ${ }^{27}$, sin contar la sección fija de la «Revista de la semana», en la que, curiosamente, Ruiz Aguilera también respetará la estructura interna que le dio Fernández Cuesta, dejando para el final la crítica de las novedades teatrales.

Tampoco aportarían novedades importantes los últimos directores literarios de El Museo: Francisco Giner de los Ríos, al que, eso sí, la recién conquistada libertad de prensa le permitirá criticar al gobierno desde la Revista ${ }^{28}$, se hará cargo de la dirección literaria a partir del n 42 de 1868, y será sustituido

«El Museo, tal vez cometiendo una indiscreción, se ha aventurado alguna vez a alargar el cuello y meter un poco la cabeza por la entreabierta puerta de la política. Después de haberle dado repetidas veces, como vulgarmente se dice, con la puerta en los hocicos, ha decidido la enmienda, sentándose en el dintel para descansar un momento, y una vez descansado, tomando el rumbo para otra parte». Y en el n 22 vuelve a insistir en este asunto, afirmando que recurre a hablar del tiempo porque sobre «asuntos interiores» a El Museo no se le permite ni repetir por la tarde lo que todos han dicho por la mañana.

27. Se crean también categorías como combinaciones de las anteriores: «Viajes y Monumentos artísticos», «Historia y Costumbres»o «Geografía e Historia». Y otros epígrafes presentan sutiles variantes: «Monumentos españoles antiguos», «Monumentos arquitectónicos», «Edificios públicos» o «Crítica histórica».

28. Tampoco hay que menospreciar este significativo detalle. Los cambios políticos radicales que se vivían entonces en España (paso de la Monarquía al Sexenio Democrático) dejarían esta huella en nuestra revista: si, a la hora de hablar de la actualidad, la regla general durante toda la trayectoria de El Museo Universal había sido limitarse a los asuntos internacionales y apenas aludir veladamente a los temas españoles, a partir de la Revolución del 68 la actualidad política española entra en los contenidos habituales de la publicación, y no solo en los comentarios de la Revista de la Semana, sino también en forma de grabados, con sus correspondientes textos explicativos, que van a retratar revueltas y otras movilizaciones sociales. 
en el $\mathrm{n}^{\circ} 1$ de 1869 por Nicolás Díaz Benjumea ${ }^{29}$, quien permanecerá hasta el $\mathrm{n}^{\circ} 34$ del mismo año (con la excepción del n. ${ }^{\circ} 30$, cuya revista la firma Moreno Godino) para dejar ya paso al último revistero de El Museo Universal: el N. C. al que hemos hecho referencia algo más arriba.

En definitiva, $\tan$ solo hubo dos cambios verdaderamente notables en la trayectoria de El Museo Universal, y ambos fueron implantados en el $n .{ }^{\circ} 1$ de 1860: a partir de ese número, como decíamos, la publicación pasó a tener periodicidad semanal, y la «Revista de la semana» se trasladó a la primera plana. Por lo demás, El Museo Universal se presenta como un proyecto compacto y notablemente estable a lo largo del tiempo, a pesar de los numerosos directores literarios que sucedieron a Fernández Cuesta.

Ya con la perspectiva necesaria, y a modo de conclusión, podemos afirmar que El Museo Universal no es un periódico sobre artes ni sobre ciencias; tampoco es propiamente un periódico literario, pues da cabida a otros muchos asuntos y a infinidad de textos «no literarios»; tampoco es un periódico noticiero ni político. Diremos, sin embargo, que incluye todos los asuntos anteriores, inclusive la política, evitando la censura mediante diversos subterfugios (alusiones indirectas, lítotes, etc.) o enfrentándola directamente hasta 1868, pues a partir de la revolución los contenidos políticos pasarán a ser permitidos y abiertamente expresados en El Museo.

\section{¿Cuál es pues la naturaleza de El Museo Universal?}

Se trata, ante todo, de una revista «ilustrada»: sus grabados, de una calidad inédita en España, son la esencia de la publicación, la característica que la diferencia del resto de los periódicos de su época. Los asuntos retratados en estos grabados son variadísimos: personalidades, edificios monumentales (especialmente abundantes), inventos y progresos técnicos, hallazgos

29. En la Ilustración Española y Americana del 22 de julio de 1884, con motivo del fallecimiento de Benjumea, Narciso Campillo publica unos «apuntes biográficos» sobre el escritor en los que se afirma que nació en Sevilla el 9 de marzo de 1829 y murió en Barcelona el 8 de marzo de 1884 antes de cumplir los 55 años. Estudió la carrera de Jurisprudencia en su ciudad natal, donde ya empezó a destacar como literato. Su principal legado fueron sus originales estudios de la obra cervantina, como La estafeta de Urganda, Corona de Alquife, El mensaje de Merlín y La verdad sobre el Quijote. Sobre otros asuntos publicó Las costumbres del Universo, El Solterón, Catecismo filosófico, El Palmerín de Inglaterra, La Mitología de la Revolución, Cartilla para electores, Gibraltar a España, Ingenio político de la nación española y La Cuestión del día. Residió en Londres, donde fundó y redactó casi por entero El Fígaro, y dirigió Ecos de Ambos Mundos. De regreso en España, fundó La Unión y dirigió El Museo Universal. Colaboró con multitud de periódicos literarios, y en el momento de su muerte dirigía en Barcelona La Ilustración de la Mujer. Publicó también poesía: El Suplicio de los Comuneros, Las dos Reinas, y A Tassara. Fue abogado del Ilustre Colegio de Madrid, socio profesor de la Academia de Jurisprudencia y Legislación y académico de la Real de Ciencias de Lisboa. 
arqueológicos, acontecimientos de actualidad, tipos regionales, costumbres populares, etc., de manera que el título de la revista acaba siendo su mejor definición: es un verdadero «museo universal» en el sentido de que es un compendio de imágenes variadísimas; una suerte de caótica enciclopedia visual de su tiempo.

En todo caso, los textos que acompañaron a estos grabados, junto a la creación literaria raramente ilustrada, alcanzaron bajo la dirección de Nemesio Fernández Cuesta una calidad lo bastante notable como para multiplicar el prestigio de El Museo Universal, que llegó a ser visto por sus contemporáneos como un importante "periódico literario».

¿Hubo por detrás de esta enorme masa heterogénea de textos e imágenes alguna directriz o línea editorial o apenas se intentó abarcar todo, como sugiere el propio título de la revista?

La gran línea maestra, declarada en la propia publicación, que orienta la elección de contenidos, es un nacionalismo integrador que pretende sumar, atesorar y conservar (como en un museo) todas las riquezas regionales de España: arquitectura, folclore, lenguas, literatura, antigüedades... Resulta curioso notar la coincidencia con el programa del costumbrismo no apenas en el afán de salvar del paso del tiempo todas las realidades españolas amenazadas por la modernidad uniformadora, sino también en el hecho de que El Museo Universal, al igual que el costumbrismo descrito por Mesonero Romanos en el prólogo a su Panorama matritense, se presenta como reacción ante las opiniones extranjeras sobre España, frecuentemente inexactas, cuando no falaces, que requerirían de una corrección realizada desde la propia España (Marco, 1987).

Se percibe, en efecto, en la globalidad de El Museo Universal, un nacionalismo a la defensiva, junto a un sentimiento de inferioridad frente a los países más poderosos y avanzados de Europa que quiere vencerse. Esto contrasta con una suerte de orgullo u optimismo de época que también envuelve la publicación, si bien posiblemente este otro sentimiento debería restringirse y matizarse: hay una fe sin fisuras en el progreso, que llega a provocar fascinación y entusiasmo a la hora de hablar de los adelantos técnicos, pero no debe olvidarse que este progreso es el provocado apenas en Occidente por la Segunda Revolución Industrial, de manera que el orgullo al que nos referimos se basa en pertenecer al continente, a la raza e incluso a la clase social que ha protagonizado e impulsado estos avances que se ven como prodigiosos. En España, no obstante, esta euforia tendría sus grandes zonas de sombra, pues 
la participación del país en todos estos logros fue muy limitada ${ }^{30}$, situándose en el furgón de cola del progreso: la repentina aceleración de la Historia que avino con la industrialización dejó a España enseguida muy atrás, de manera que los viajeros extranjeros que cada vez llegaban a España en mayor número siempre se llevaban la impresión de haber visitado un territorio al margen del progreso e incluso, para los más hiperbólicos, al margen de la civilización, lo que, no obstante, para algunos suponía justamente el especial encanto de esta tierra.

El Museo Universal es una compleja manifestación cultural de esta fase de la historia de España y, como tal, tiene de hecho innumerables muestras de ese binomio sentimental que acabo de describir: un optimismo amargo, o una amargura esperanzada y orgullosa. Pero este sentimiento paradójico que reina en El Museo no es suficiente para explicar el enorme volumen de textos y grabados publicados de 1857 a 1869: a pesar de tener objetivos ideológicos bien definidos, El Museo Universal también estará siempre muy atento al interés y a la demanda de su público, y hará lo posible por satisfacerlo ofreciéndole lo que pide: instrucción, entretenimiento, ciertas dosis de escapismo y, por supuesto, imágenes.

\section{Bibliografía citada}

B. MÁrquez, Miguel, «D. Aberlardo de Campos y la Ilustración Española y Americana», Ámbitos, nº 13-14, 2005, pp. 185-209.

CubRíA, María José, «Heine y Augusto Ferrán. El Lyrisches Intermezzo y Die Heimkehr en La Soledad», Revista de Filología Alemana, 1999, 7, pp. 105-124.

ENGLEKIRK, John, «El Museo Universal (1857-69): Mirror of Transition Years», PMLA, Vol. 70, n. ${ }^{\circ} 3$ (Jun., 1955), pp. 350-374.

Gómez Aparicio, Pedro, Historia del Periodismo Español, Editora Nacional, Madrid, 1967.

MARCO, Joaquín, «El costumbrismo español como reacción» en AA. VV., La imagen de Andalucía en los viajeros románticos, Málaga, Diputación, 1987, pp. 125-139. (apud Romero, Leonardo, Panorama crítico del romanticismo español, Editorial Castalia, Madrid, 1994, pp.403-404).

30. En la Exposición Universal de Londres de 1862, España apenas destacó por sus espadas toledanas, sus sedas, sus encajes y sus productos agrícolas ( «La esposición universal de Londres, España y Portugal, XI», por J. S. Bazán, El Museo Universal, n. ${ }^{\circ} 48$ de 1862). De la misma forma, el espacio físico que se concedió a España en la Exposición Universal de París de 1867 fue muy escaso en comparación al de otras naciones, lo que despertaba la vergüenza y el rencor de los visitantes españoles (ver S., «Exposición Universal de 1867», El Museo Universal, nº 18 de 1867). 
MARTínez MARTín, Jesús A., «La edición artesanal y la construcción del mercado», en Jesús A. Martínez Martín (Dir.), Historia de la edición en España, 18361936, Marcial Pons, Madrid, 2001.

OSSORIO Y BERNARD, Manuel, Ensayo de un catálogo de periodistas españoles del siglo XIX, Imprenta y Litografía de J. Palacios, Madrid, 1903.

PÁEz Ríos, Elena: El Museo Universal. Madrid (1857-1869). (Colección de Índices de Publicaciones Periódicas / dirigida por Joaquín Entrambasaguas, n. ${ }^{\circ} \mathrm{XIV}$ ). C.S.I.C., Madrid, 1952.

RIEGo, Bernardo, La construcción social de la realidad a través de la fotografía y el grabado, Ed. Universidad de Cantabria, 2001.

SEOANE, María Cruz, Historia del periodismo en España, Alianza Editorial, Madrid, 1968.

Valls, Josep Francesc, Prensa y burguesía en el siglo XIX español, Anthropos, Barcelona, 1988.

Fecha de recepción: 25/07/2014

Fecha de aceptación: 06/08/2014 